\title{
Bioactivities of Triterpenes and a Sterol from Syzygium samarangense
}

Dennis D. Raga ${ }^{\mathrm{a}, *}$, Candice Louise C. Cheng ${ }^{\mathrm{a}}$, Kate Catherine Ilona C. Lee ${ }^{\mathrm{a}}$, Wileen Zoe P. Olaziman ${ }^{\mathrm{a}}$, Vernon Joseph A. De Guzman ${ }^{\mathrm{a}}$, Chien-Chang Shen ${ }^{\mathrm{b}}$, Francisco C. Franco Jr. ${ }^{c}$, and Consolacion Y. Ragasa ${ }^{c}$

a Biology Department and Center for Natural Sciences and Ecological Research, De La Salle University, 2401 Taft Avenue, Manila 1004, Philippines. Fax: (+632) 536.0228. E-mail: dennis.raga@dlsu.edu.ph

b National Research Institute of Chinese Medicine, 155-1, Li-Nong St., Sec 2, Taipei 112, Taiwan

c Chemistry Department and Center for Natural Sciences and Ecological Research, De La Salle University, 2401 Taft Avenue, Manila 1004, Philippines

* Author for correspondence and reprint requests

Z. Naturforsch. 66c, 235-244 (2011); received October 20/December 16, 2010

Cycloartenyl stearate (1a), lupenyl stearate (1b), sitosteryl stearate (1c), and 24-methylenecycloartanyl stearate (1d) (sample 1) from the air-dried leaves of Syzygium samarangense exhibited potent analgesic and anti-inflammatory activities at effective doses of $6.25 \mathrm{mg} / \mathrm{kg}$ body weight and $12.5 \mathrm{mg} / \mathrm{kg}$ body weight, respectively. Sample 1 also exhibited negligible toxicity on zebrafish embryonic tissues. There were incidences of mortality upon direct exposure of sample 1 to dechorionated embryos, but higher mortality and aberration were observed during intact chorion treatment.

Key words: Syzygium samarangense, Analgesic, Anti-Inflammatory, Zebrafish Toxicity

\section{Introduction}

Syzygium samarangense (syn. Eugenia javanica Linn.), commonly known as makopa, is grown throughout the Philippines for its fruits. The leaves are used as an antipyretic and a diuretic (Kuo et al., 2004). The flowers of S. samarangense are used for the treatment of fever and diarrhea. Four flavonoids isolated from the hexane extract of $S$. samarangense showed dose-dependent spasmolytic activity (Ghayur et al., 2006). Another study reported that $2^{\prime}, 4^{\prime}$-dihydroxy-6'-methoxy3',5'-dimethylchalcone from $S$. samarangense exhibited significant differential cytotoxicity against the MCF-7 cell line and significant selective cytotoxicity against the RAD 52 yeast mutant strain (Amor et al., 2007). The following compounds isolated from the hexane extract of the leaves of $S$. samarangense: $\alpha$ - and $\beta$-carotene, lupeol, betulin, epi-betulinic acid, 2', 4'-dihydroxy$6^{\prime}$-methoxy-3'-methylchalcone, $2^{\prime}, 4^{\prime}$-dihydroxy-6'methoxy-3'-methyldihydrochalcone, 2'-hydroxy4',6'-dimethoxy-3'-methylchalcone, and $\beta$-D-sitosterylglucoside exhibited significant and selective inhibition of prolyl endopeptidase (Amor et al., 2004). An earlier study reported that the metha- nol extract of S. samarangense leaves exhibited high antidiabetic activity (Villasenor et al., 1998). A recent study reported that $2^{\prime}, 4^{\prime}$-dihydroxy-6'methoxy-3',5'-dimethylchalcone and 5-O-methyl4'-desmethoxy matteucinol from $S$. samarangense significantly lowered the blood glucose levels in hyperglycaemic mice when administered 15 min after glucose load, while 2',4'-dihydroxy-6'methoxy-3',5'-dimethylchalcone significantly lowered the blood glucose levels of alloxan diabetic mice (Resurreccion-Magno et al., 2005).

We report here the analgesic, anti-inflammatory, and toxic properties of a mixture of cycloartenyl stearate (1a), lupenyl stearate (1) $)$, sitosteryl stearate (1c), and 24-methylenecycloartanyl stearate (1d) (Fig. 1) from the dichloromethane extract of the air-dried leaves of Syzygium samarangense.

\section{Materials and Methods}

\section{General experimental procedures}

NMR spectra were recorded on a Varian Unity Inova (Palo Alto, CA, USA) spectrometer in $\mathrm{CDCl}_{3}$ at $500 \mathrm{MHz}$ for ${ }^{1} \mathrm{H} \mathrm{NMR}$ and $125 \mathrm{MHz}$ for ${ }^{13} \mathrm{C}$ NMR spectra. MS was done on a Finnigan MAT LCQ mass spectrometer (San Jose, CA, 

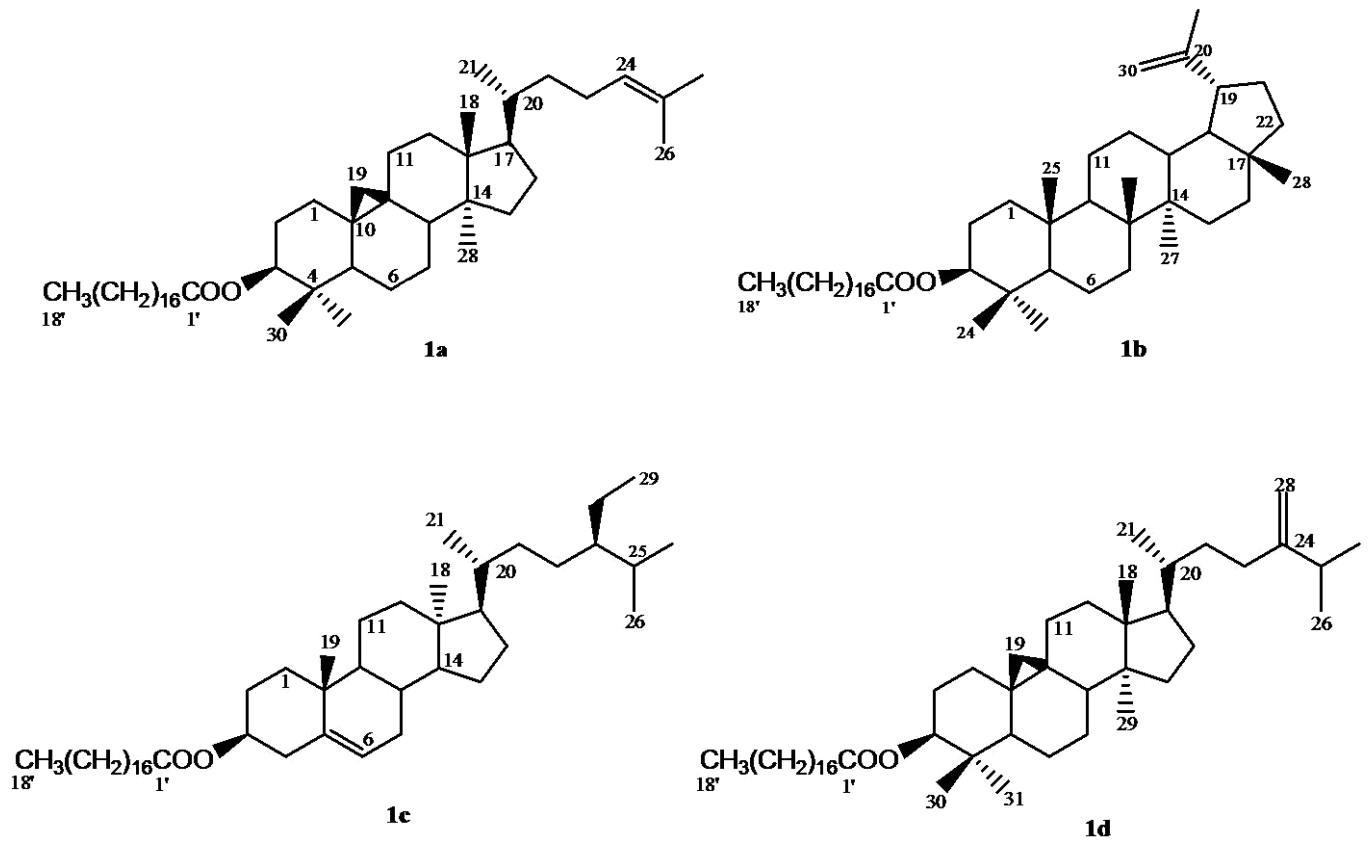

Fig. 1. Chemical structures of three triterpenes and a sterol: cycloartenyl stearate (1a), lupenyl stearate (1b), sitosteryl stearate (1c), and 24-methylenecycloartanyl stearate (1d) obtained from the leaves of S. samarangense.

USA). Column chromatography was performed with silica gel 60 (70-230 mesh) (Merck, Darmstadt, Germany). TLC was performed with plastic backed plates coated with silica gel $\mathrm{F}_{254}$ (Merck); plates were visualized by spraying with vanillin sulfuric acid, followed by warming.

\section{Sample collection}

Fresh leaves $(5 \mathrm{~kg})$ of Syzygium samarangense (Blume) Merr. et Perry were collected from Antipolo City, Philippines in April 2009. Voucher specimens were identified and authenticated by Ramon Bandong of the Jose Vera Santos Museum, Institute of Biology, University of the Philippines, Diliman, Philippines and deposited at the Chemistry Department of De La Salle University, Manila, Philippines (voucher number 155).

\section{Isolation}

The air-dried S. samarangense leaves $(1 \mathrm{~kg})$ were ground in an osterizer, soaked in dichloromethane (DCM) for $3 \mathrm{~d}$, and then filtered. The filtrate was concentrated under reduced pressure to afford a crude extract ( $45.86 \mathrm{~g}$ ) which was chromatographed with increasing portions of acetone in DCM at $10 \%$ increment. The DCM and
$10 \%$ acetone in DCM fractions were combined and rechromatographed in petroleum ether. The more polar fractions were rechromatographed in ethyl acetate with increasing percentage of petroleum ether $(0.5 \%, 1 \%, 2.5 \%$, and $5 \%)$ to afford sample 1 which is a mixture of $\mathbf{1 a - 1 d}(1.0 \mathrm{~g})$.

Cycloartenyl stearate $(\mathbf{1 a}):{ }^{13} \mathrm{C}$ NMR: $\delta(\mathrm{ppm})=$ 31.6 (C-1), 26.8 (C-2), 80.3 (C-3), 39.5 (C-4), 47.2 (C-5), 20.9 (C-6), 28.1 (C-7), 47.8 (C-8), 20.1 (C-9), 26.0 (C-10), 25.8 (C-11), 35.6 (C-12), 45.3 (C-13), 48.8 (C-14), 32.8 (C-15), 26.5 (C-16), 52.2 (C-17), 18.0 (C-18), 29.8 (C-19), 35.9 (C-20), 18.3 (C-21), 36.3 (C-22), 25.2 (C-23), 125.2 (C-24), 130.8 (C25), 17.6 (C-26), 25.7 (C-27), 19.3 (C-28), 15.2 (C-29), 25.4 (C-30), 173.6 (C-1'), 34.8 (C-2'), 31.9 (C-3'), 22.7, 25.2, 29.2-29.7 (C-4'-C-17'), 14.1 (C18 ').

Lupenyl stearate $(\mathbf{1 b}):{ }^{13} \mathrm{C}$ NMR: $\delta(\mathrm{ppm})=37.8$ (C-1), 23.4 (C-2), 80.7 (C-3), 38.54 (C-4), 55.5 (C5), 18.3 (C-6), 34.3 (C-7), 40.9 (C-8), 50.4 (C-9), 38.1 (C-10), 21.0 (C-11), 25.2 (C-12), 37.2 (C-13), 42.7 (C-14), 27.5 (C-15), 35.6 (C-16), 43.0 (C-17), 48.4 (C-18), 48.0 (C-19), 150.8 (C-20), 29.4 (C-21), 40.0 (C-22), 27.5 (C-23), 16.3 (C-24), 16.3 (C-25), 16.3 (C-26), 14.5 (C-27), 18.3 (C-28), 19.4 (C-29), 
109.4 (C-30), 173.5 (C-1'), 34.8 (C-2'), 31.9 (C-3'), 22.7, 25.2, 29.2-29.7 (C-4'-C-17'), 14.1 (C-18').

Sitosteryl stearate $(\mathbf{1 c}):{ }^{13} \mathrm{C}$ NMR: $\delta(\mathrm{ppm})=$ 37.1 (C-1), 27.8 (C-2), 73.6 (C-3), 38.0 (C-4), 139.7 (C-5), 122.6 (C-6), 31.92 (C-7), 31.89 (C-8), 50.0 (C-9), 36.1 (C-10), 21.0 (C-11), 39.7 (C-13), 42.3 (C-14), 56.7 (C-15), 24.3 (C-16), 28.2 (C-17), 56.0 (C-18), 12.0 (C-19), 19.3 (C-20), 36.6 (C-21), 18.8 (C-22), 33.9 (C-23), 26.1 (C-24), 45.8 (C-25), 29.2 (C-26), 19.0 (C-27), 19.8 (C-28), 23.1 (C-29), 11.8 (C-30), 173.6 (C-1'), 34.8 (C-2'), 31.9 (C-3'), 22.7, 25.2, 29.2-29.7 (C-4'-C-17'), 14.1 (C-18').

24-Methylenecycloartanyl stearate $(\mathbf{1 d}):{ }^{13} \mathrm{C}$ NMR: $\delta(\mathrm{ppm})=31.6(\mathrm{C}-1), 26.8(\mathrm{C}-2), 80.6(\mathrm{C}-$ 3), 39.5 (C-4), 47.2 (C-5), 20.9 (C-6), 25.8 (C-7), 47.9 (C-8), 20.1 (C-9), 26.1 (C-10), 26.5 (C-11), 32.8 (C-12), 45.3 (C-13), 48.8 (C-14), 35.5 (C-15), 28.1 (C-16), 52.2 (C-17), 18.0 (C-18), 29.7 (C-19), 36.1 (C-20), 18.3 (C-21), 35.0 (C-22), 31.6 (C-23), 156.8 (C-24), 33.8 (C-25), 21.9 (C-26), 22.0 (C-27), 105.9 (C-28), 19.3 (C-29), 15.2 (C-30), 25.4 (C-31), 173.6 (C-1'), 34.8 (C-2'), 31.9 (C-3'), 22.7, 25.2, 29.2-29.7 (C-4'-C-17'), 14.1 (C-18')

\section{Sample preparation}

In the mouse models, the samples were freshly prepared by dissolving the sample in Polysorbate 80 (Tween-80; AJAX, Finechem Pty. Ltd., Taren Point, NSW, Australia) to obtain a dose of $100 \mathrm{mg} /$ $\mathrm{kg}$ body weight (BW), followed by serial dilution with Polysorbate 80 to obtain doses of $6.25,12.5$, 25 , and $50 \mathrm{mg} / \mathrm{kg} \mathrm{BW}$. In the zebrafish toxicity model, the samples were prepared fresh by dissolving the sample in $100 \%$ DMSO (dimethyl sulfoxide) followed by serial dilution with embryo media to obtain $5,10,20$, and $50 \mu \mathrm{g} / \mathrm{mL}$ at a final solvent content of $0.01 \%$.

\section{Experimental animals}

A total of 119 male ( 8 weeks old) ICR albino mice (Mus musculus L.) weighing $(19.0 \pm 2.0)$ $\mathrm{g}$ were acclimatized for $7 \mathrm{~d}$ prior to conducting the bioassay. The animals were obtained from the Bureau of Food and Drugs, Muntinlupa City, Philippines and housed at the animal containment unit of De La Salle University, Manila, Philippines with $12 \mathrm{~h}$ daylight and $12 \mathrm{~h}$ darkness and free access to food pellets and water. A 13-h fasting period was kept prior to each treatment procedure followed by $2 \mathrm{~h}$ for acclimatization pri- or to each bioassay. Wild-type zebrafish embryos were obtained from adult mating, raised at $28^{\circ} \mathrm{C}$ as described by Westerfield (2007), and staged according to Kimmel et al. (1995). Synchronized embryos were collected, dechorionated, and arrayed by a pipette at three embryos per well. All procedures were in accordance with the existing guidelines of the Philippine Association of Laboratory Animal Science (PALAS, 2002) for care and use of laboratory animals and with Administrative Order 40 of the Bureau of Animal Industry relative to Republic Act No. 8485 .

\section{Antinociceptive activity}

The tail flick assay (Grotto and Sulman, 1967) was conducted on mice $(n=14)$ orally administered with diclofenac $(7.14 \mathrm{mg} / \mathrm{kg} \mathrm{BW})$ (GX International, Muntinlupa City Philippines) and Polysorbate $80(0.5 \mathrm{~mL} / 20 \mathrm{~g} \mathrm{BW})$ as the positive and negative controls, respectively, and four dosages of sample 1 dissolved in Polysorbate 80. One-third of the distal part of the tail was immersed in a warm water bath $\left(50^{\circ} \mathrm{C}\right) 1 \mathrm{~h}$ after the treatments. The time the mouse withdrew its tail from the water bath was noted. Percent inhibition was calculated according to the equation: \%inhibition $=100-$ [(time that the experimental mice attempted to remove their tails/average time that the control mice attempted to remove their tails) $\cdot 100]$.

The acetic acid writhing assay (Raga et al., 2010; Ragasa et al., 2008, 2009) was performed. The test animals $(n=14)$ were orally administered with Polysorbate 80 and diclofenac sodium difenax for the negative and positive controls, respectively, as well as with four dosages of sample 1 . After $1 \mathrm{~h}$ of treatments, the mice were injected intraperitoneally with $1 \%$ glacial acetic acid (Mallinckrodt Chemicals, Pittsburg, NJ, USA). Abdominal stretches of the mice were counted within $10 \mathrm{~min}$ upon injection and calculated as the percent inhibition.

\section{Anti-inflammatory activity}

The modified antipleurisy assay (Ragasa et al., 2008, 2009) was performed. The test animals $(n=9)$ were subjected to light anesthesia with diethyl ether (AJAX, Finechem Pty. Ltd). Immediately after the mice became unconscious, $1 \%$ $\kappa$-carrageenan $(0.15 \mathrm{~mL}$; Marine Development Resources, Quezon City, Philippines) in normal saline solution was carefully injected into the pleural cavity along the right flank of the test ani- 
mal. One $\mathrm{h}$ after induction of pleurisy, the four dosages of sample 1 were orally administered to the test animals. Polysorbate 80 and diclofenac were used as negative and positive controls, respectively. After another hour, the mice were sacrificed by intraperitoneal injection of $70 \%$ ethanol. The pleural cavity of each mouse was opened and washed with $100 \mu \mathrm{L}$ citrate buffer to collect lung exudates. A portion of the exudates $(20 \mu \mathrm{L})$ was obtained for white blood cell (WBC) count using an improved Neubauer hemocytometer following a double blind method. In five $1-\mathrm{mm}$ squares of each of the two counting chambers, the number of cells was then counted and computed using the following formula: cell concentration $=$ (no. of cells - dilution factor - 10)/(no. of large hemocytometer squares counted).

Another portion of the exudates $(10 \mu \mathrm{L})$ was taken and smeared on a glass slide. The slides were fixed in absolute methanol, then stained using Giemsa solution $\left(4 \mathrm{mg} / \mathrm{mL}\right.$ in $\mathrm{MeOH} / \mathrm{H}_{2} \mathrm{O}$, $7: 3$ ) for $5 \mathrm{~min}$, and finally rinsed in tap water. Polymorphonuclear cells were identified and counted as the maximum percentage anti-inflammatory effect following a double blind method.

\section{Zebrafish toxicity screen (Kitambi et al., 2009).}

Two experiments were performed to determine the toxicity of the test samples on developing zebrafish embryos. Experiment 1 was performed on dechorionated and non-dechorionated 24-hourspost-fertilization (hpf) embryos, while experiment 2 was performed on dechorionated and non-dechorionated 36-hpf embryos. The test samples were administered at the beginning of each time point. Observations were made after every $24 \mathrm{~h}$ until the end of a 72-h observation period. The embryos were photodocumented using a Nikon StereoZoom100 camera (Kanagawa, Japan). Mortality and signs of abnormal development were noted.

\section{Statistical analysis}

The results were analysed using SPSS ver. 13 for Windows. One way analysis of variance was performed to determine the significant effects of the analgesic and anti-inflammatory potentials of sample 1 . The results were considered significant at $P \leq 0.05$. Significant differences between groups were determined by post hoc analysis at 95\% Duncan multiple range finding test. Means are present as mean $\pm \mathrm{SD}$.

\section{Results}

\section{Identification of compounds}

Silica gel chromatography of the dichloromethane extract of the air-dried leaves of S. samarangense afforded a mixture of cycloartenyl stearate (1a), lupenyl stearate (1b), sitosteryl stearate (1c), and 24-methylenecycloartanyl stearate (1d). Their structures (Fig. 1) were elucidated by extensive 1D and 2D NMR spectroscopy. The fatty acid chain length was determined by the mass spectrum of sample 1 which gave a molecular ion peak at $m / z=694.2$ corresponding to the molecular formula $\mathrm{C}_{48} \mathrm{H}_{86} \mathrm{O}_{2}$ and an $\left[\mathrm{M}^{+}-\mathrm{C}_{18} \mathrm{H}_{35} \mathrm{O}_{2}\right]$ peak of $\mathrm{m} / \mathrm{z}$ 409 which resulted from the loss of stearic acid .

The ${ }^{1} \mathrm{H}$ NMR spectrum of sample 1 indicated resonances for a mixture of compounds as deduced from the integrals and disparity of the single hydrogen peaks. The structure of $\mathbf{1 a}$ was confirmed by comparison of the ${ }^{13} \mathrm{C}$ NMR data of 1a with those of cycloartenyl acetate (De Pascual Teresa et al., 1987) for the triterpene part and the fatty acid ester 16-hydroxycycloartenyl palmitate (Ragasa et al., 2004) for the fatty acid part, which matched in all essential respects. The structures of $\mathbf{1 b}$ and $\mathbf{1 d}$ were confirmed by comparison of their ${ }^{13} \mathrm{C}$ NMR data with those of lupenyl acetate (Liu et al., 1998) and 24-methylenecycloartanyl acetate (Ragasa et al., 2005) for the triterpene part and the fatty acid ester 16-hydroxycycloartenyl palmitate (Ragasa et al., 2004) for the fatty acid part. The spectra matched in all essential respects. The ${ }^{13} \mathrm{C}$ NMR data of $\mathbf{1 c}$ matched those of sitosteryl palmitate (Parmar et al., 1998), confirming its structure.

\section{Analgesic property}

The test animals did not exhibit any sign of poisoning such as weight loss, poor grooming, depression, slow reflex response, and other behavioural manifestations of intoxication (Guevarra et al., 2005). These behaviours indicate that the doses administered were below the toxic level. Acute investigation of the antinociceptive potential of sample 1 from S. samarangense significantly reduced perception of pain in the visceral model $(P=0.0001)$ comparable to the effects of diclofenac, but minimal inhibition was observed in the thermal pain model $(P=0.0001)$ (Table I).

In the visceral pain model (acetic acid writhing assay), mice administered with all doses of sample 
Table I. Analgesic properties of sample 1.

\begin{tabular}{lrrrrr}
\hline Treatment & \multicolumn{2}{c}{ Tail flick } & & \multicolumn{2}{c}{ Acetic acid writhing assay } \\
\cline { 2 - 3 } \cline { 5 - 6 } & Time [s] & Inhibition $(\%)$ & & Frequency $(f)$ & Inhibition $(\%)$ \\
\hline Negative (P80) & $3.20 \pm 0.18$ & $-9.09 \pm 6.98^{\mathrm{c}}$ & & $28.45 \pm 2.21$ & $-0.02 \pm 7.76^{\mathrm{b}}$ \\
Diclofenac & $5.37 \pm 0.28$ & $35.97 \pm 3.61^{\mathrm{a}}$ & & $13.74 \pm 1.40$ & $51.71 \pm 4.93^{\mathrm{a}}$ \\
$6.25 \mathrm{mg} \mathrm{sample} \mathrm{1/kg} \mathrm{BW}$ & $4.05 \pm 0.41$ & $9.75 \pm 9.80^{\mathrm{b}}$ & & $16.79 \pm 2.65$ & $41.0 \pm 9.32^{\mathrm{a}}$ \\
$12.5 \mathrm{mg} \mathrm{sample} \mathrm{1/kg} \mathrm{BW}$ & $4.37 \pm 0.45$ & $22.80 \pm 4.98^{\mathrm{ab}}$ & & $18.36 \pm 2.92$ & $35.48 \pm 10.26^{\mathrm{a}}$ \\
25 mg sample 1/kg B & $3.80 \pm 0.30$ & $26.13 \pm 6.84^{\mathrm{ab}}$ & & $18.36 \pm 2.45$ & $35.48 \pm 8.64^{\mathrm{a}}$ \\
$50 \mathrm{mg}$ sample 1/kg BW & $4.0 \pm 0.32$ & $24.50 \pm 4.20^{\mathrm{ab}}$ & & $20.14 \pm 2.74$ & $29.20 \pm 9.62^{\mathrm{a}}$ \\
100 mg sample 1/kg BW & $3.77 \pm 0.23$ & $18.30 \pm 3.40^{\mathrm{ab}}$ & & $17.07 \pm 1.80$ & $40.0 \pm 6.32^{\mathrm{a}}$ \\
\hline
\end{tabular}

Means followed by the same letter are not significantly different at 95\% DMRT $(\alpha=0.05)$.

Table II. Anti-inflammatory property of sample 1.

\begin{tabular}{|c|c|c|c|c|}
\hline \multirow[t]{2}{*}{ Treatment } & \multicolumn{2}{|c|}{ WBC smear count } & \multicolumn{2}{|c|}{ WBC hemocytometer count } \\
\hline & Mean & Inhibition (\%) & Mean & Inhibition (\%) \\
\hline Polysorbate 80 & $288.11 \pm 17.71$ & $0.0004 \pm 6.15^{\mathrm{b}}$ & $120.30 \pm 18.38$ & $0.00 \pm 15.28^{\mathrm{b}}$ \\
\hline Diclofenac & $61.67 \pm 9.73$ & $76.60 \pm 3.38^{\mathrm{a}}$ & $41.56 \pm 5.98$ & $65.46 \pm 4.97^{\mathrm{a}}$ \\
\hline $12.5 \mathrm{mg}$ sample $1 / \mathrm{kg} \mathrm{BW}$ & $122.56 \pm 16.44$ & $57.46 \pm 5.70^{\mathrm{a}}$ & $53.11 \pm 9.94$ & $55.85 \pm 8.26^{\mathrm{a}}$ \\
\hline $25 \mathrm{mg}$ sample $1 / \mathrm{kg} \mathrm{BW}$ & $78.13 \pm 19.32$ & $72.88 \pm 6.71^{\mathrm{a}}$ & $65.50 \pm 7.80$ & $45.55 \pm 6.48^{\mathrm{a}}$ \\
\hline $50 \mathrm{mg}$ sample $1 / \mathrm{kg} \mathrm{BW}$ & $114.00 \pm 16.22$ & $60.43 \pm 5.63^{\mathrm{a}}$ & $60.00 \pm 9.28$ & $50.12 \pm 7.71^{\mathrm{a}}$ \\
\hline $100 \mathrm{mg}$ sample $1 / \mathrm{kg} \mathrm{BW}$ & $81.63 \pm 18.76$ & $71.67 \pm 6.51^{\mathrm{a}}$ & $68.63 \pm 6.93$ & $42.95 \pm 5.76^{\mathrm{a}}$ \\
\hline
\end{tabular}

Means followed by the same letter are not significantly different at 95\% DMRT $(\alpha=0.05)$.

1 showed reduced writhing response similar to the effects of diclofenac $[(51.71 \pm 4.93) \%]$. However, a non-dose-dependent activity was observed with increasing doses of sample 1 . In the tail flick model, mice orally administered with diclofenac $(7.14 \mathrm{mg} / \mathrm{kg}$ BW) demonstrated delayed perception of pain $[(5.37 \pm 0.28) \mathrm{s}]$, i. e. $(35.97 \pm 3.61) \%$ inhibition compared to the negative control. Minimal inhibitory activity, however, was observed with all doses of sample 1, thus demonstrating low antinociceptive activity (Table I).

\section{Anti-inflammatory activity}

The anti-inflammatory activity of sample 1 was investigated using the lung antipleurisy model in mice. Quantification of leukocyte emigration into the pleural cavity using Giemsa-stained blood smear and a white blood cell (WBC) hemocytometer count were performed. Sample 1 administered orally to mice $1 \mathrm{~h}$ after induction of pleurisy revealed a significant $(P=0.0001)$ antiinflammatory activity, which is comparable to that of diclofenac (Table II). The activity was evident in the reduced number of polymorphonuclear cells that emigrated towards the site of carrageen injection. The results obtained from the WBC smear count $(P<0.0001)$ corroborated with the results obtained from the WBC hemocytometer count $(P<0.0001)$. Diclofenac reduced the test animals' sensitivity to inflammatory response with a percent inhibition of $(76.60 \pm 3.38) \%$ for the WBC smear count and $(65.46 \pm 4.97) \%$ for the WBC hemocytometer count. The administration of all doses of sample 1 has considerably reduced the concentration of WBC in the lung exudates which also corroborated with the effects observed in the visceral pain model. Furthermore, the relative anti-inflammatory activity among all doses of sample 1 indicated comparative activity to diclofenac. This also suggests that $12.5 \mathrm{mg}$ sample $1 /$ $\mathrm{kg}$ BW has high impact on the anti-inflammatory activity. The low-dose requirement necessary to elicit analgesic and anti-inflammatory potential indicates high impact potential of sample 1 .

\section{Toxicity}

Toxicity of sample 1 was analysed using zebrafish embryos with treatment administrations at $24 \mathrm{hpf}$ and $36 \mathrm{hpf}$ in the dechorionated setup. Another experiment involving 2.5-hpf embryos with intact chorion was also performed. 24-hpf embryos treated with sample 1 had higher mor- 
tality compared to the negative control. The three highest concentrations of sample 1 led to the lowest percent survival rate which is almost similar to that of the effects of the positive control $(79.167 \%)$. No mortality, however, was observed beyond 48 hpf (Fig. 2). Embryos treated with sample 1 at $36 \mathrm{hpf}$ revealed the lowest survival rate at $5 \mu \mathrm{g} / \mathrm{mL}(58.33 \%)$ and $50 \mu \mathrm{g} / \mathrm{mL}(66.67 \%)$ observed at $48 \mathrm{hpf}$. The other two concentrations of the test substance ( 10 and $20 \mu \mathrm{g} / \mathrm{mL}$ ) showed similar survival rates with the positive control, sodium lauryl sulfate (SLS) $(70.83 \%)$. There was no mortality observed at $72 \mathrm{hpf}$ (Fig. 2B). Treatment administration of sample 1 on 2.5 -hpf embryos with intact chorion revealed decreased survivability compared to the negative control group, DMSO. At $24 \mathrm{hpf}$, embryos administered with 50 and $20 \mu \mathrm{g} / \mathrm{mL}$ showed the highest mortality $(79.167 \%$ and $72.917 \%)$. Embryo survivability further decreased at $48 \mathrm{hpf}$ in all treatments except for the negative control group which remained $18.75 \%$ throughout the observation periods. The results of this study indicate that the treatments had a much higher incidence of mor- tality in the intact chorion group compared to the dechorionated embryos which may suggest that sample 1 has less severe effects on embryonic development but more on the chorionic membrane.

Three morphological abnormalities were observed at the end of the treatment periods namely: curled tail, inflamed heart, and yolk sac edema (Fig. 3). However, these morphological abnormalities observed in the treatment groups were lower than the observed values in the negative control group (DMSO) (Fig. 3). There was no incidence of malformed head observed in embryos after all treatments. These observations were almost similar in both 24-hpf and 36-hpf treatment groups. Similar to the dechorionated embryos, there was no incidence of malformed head in the intact chorion group, but an inflamed heart was observed in the 20 and $10 \mu \mathrm{g} / \mathrm{mL}$ sample 1 treatment groups along with yolk sac edema in the $20 \mu \mathrm{g} / \mathrm{mL}$ treatment group, but none were seen in both control groups. The data suggest the possible role of the chorion in protecting the developing embryo from foreign substances. In the experiments with dechorionated embryos, very little difference in

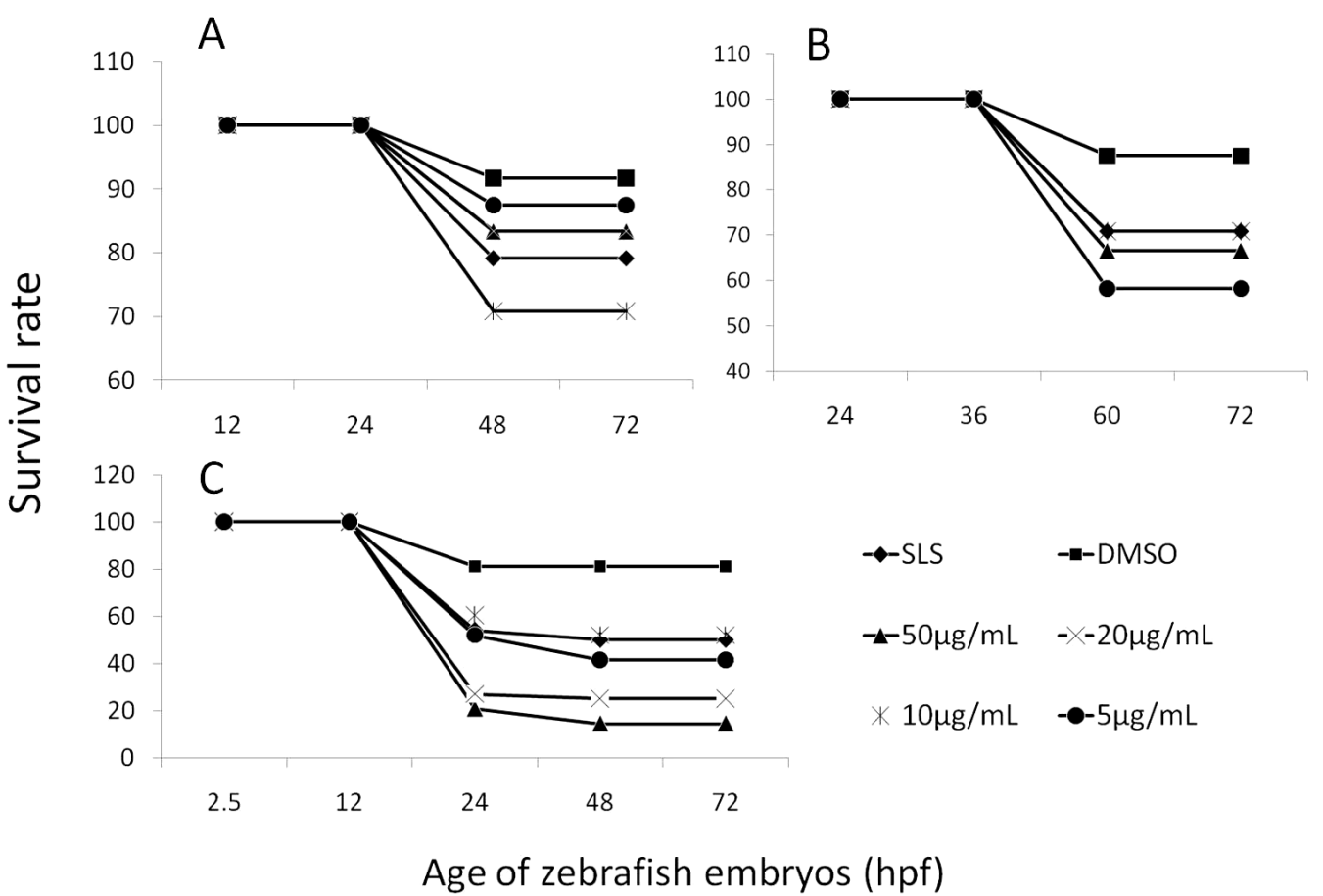

Fig. 2. Survival rate of dechorionated zebrafish embryos administered with sample 1 at (A) 24 hpf and (B) 36 hpf, and (C) zebrafish embryos with intact chorion at $2.5 \mathrm{hpf}$. SLS, sodium lauryl sulfate; DMSO, dimethyl sulfoxide. 


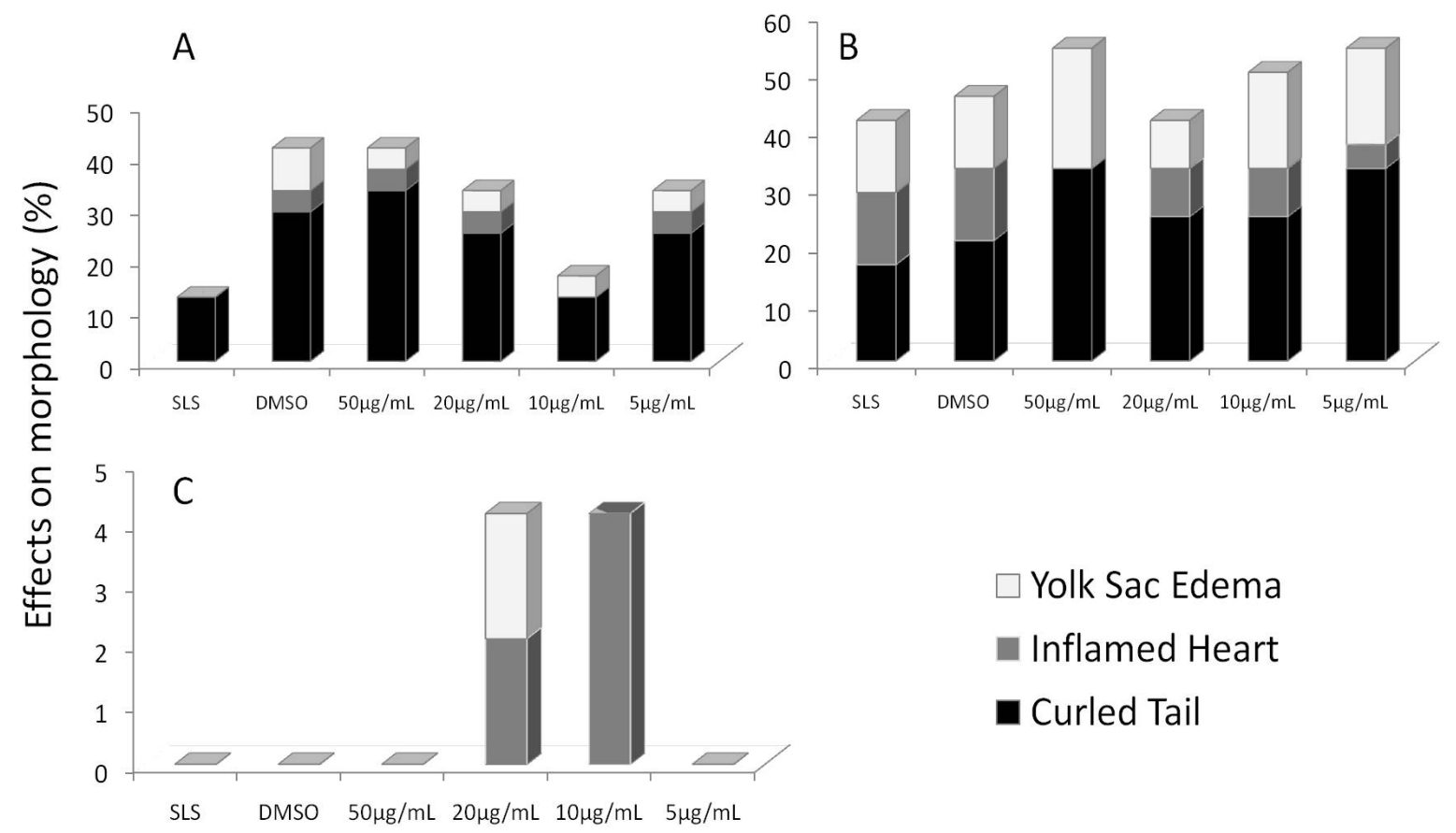

Fig. 3. Effects of sample 1 on morphology of dechorionated zebrafish embryos at (A) 24 hpf and (B) 36 hpf, and (C) zebrafish embryos with intact chorion at $2.5 \mathrm{hpf}$. SLS, sodium lauryl sulfate; DMSO, dimethyl sulfoxide.

morphological abnormality was observed across treatments indicating that these defects may not have been caused by the treatment with sample 1 , but by other external factors.

The frequency of hatching was observed and noted at $72 \mathrm{hpf}$ similar to the reported frequency of hatching in an earlier study (Kimmel et al., 1995). Most of the embryos with DMSO treat- ment hatched normally having the highest hatching frequency $(43.75 \%)$. The hatching frequency of embryos was affected by sample 1 treatments in a dose-related manner. No embryo hatched in $50 \mu \mathrm{g} / \mathrm{mL}$ treatment. The embryos in all sample 1 treatments, however, were observed alive at 72 hpf until $96 \mathrm{hpf}$, but survivability started to decrease as the age of embryo progressed (Fig. 4).

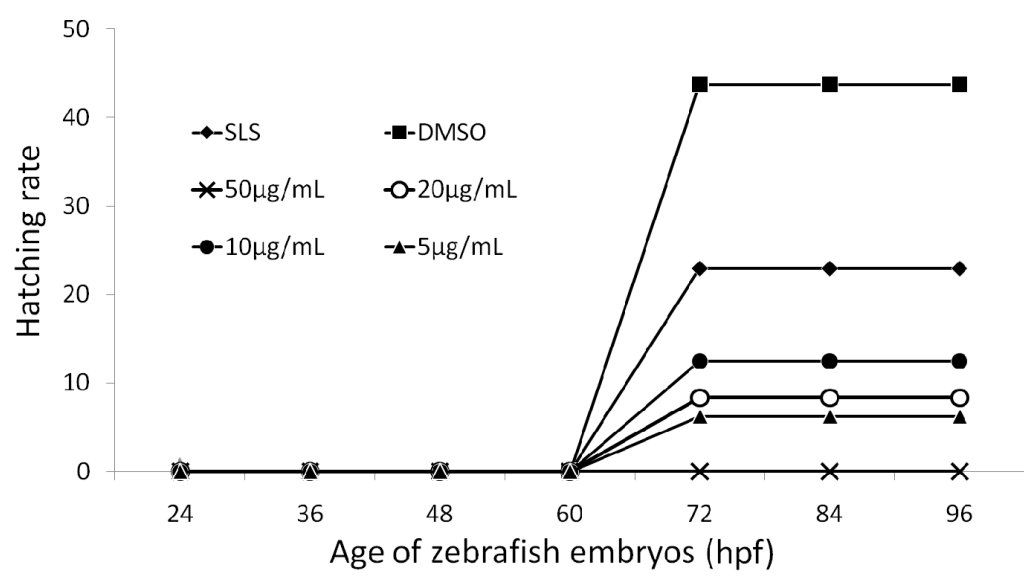

Fig. 4. Effects of sample 1 on hatching frequency of zebrafish embryos at 0.5 hpf. SLS, sodium lauryl sulfate; DMSO, dimethyl sulfoxide. 
The results of the current study indicate a possible inhibition of the normal chorionic function which may have caused significant delay in hatching and increased morphological abnormality in the embryos.

\section{Discussion}

Sample 1 obtained from S. samarangense demonstrated pain and inflammation inhibitory effects using the visceral pain model and carrageenan-induced lung pleurisy. Overall, the results illustrated a significant effect in suppressing the perception of acute pain and inflammation induced in the test animals. The tail flick assay specifically tests for centrally mediated perception of pain by inhibiting certain opioid receptors (Akter et al., 2008). The results obtained from this assay showed that the thermal response of the positive control has reduced the perception of pain in the experimental animals, but to a much lesser extent in those mice treated with sample 1 .

The acetic acid writhing assay determines the peripheral inhibition of pain by triggering the localized anti-inflammatory response that is mediated by peritoneal mast cells, acid sensing ion channels, and prostaglandin pathways which are activated when acetic acid is introduced into the system (Akter et al., 2008). No dose relationship, however, was evident in the experimental animals' response in this assay. All doses tested revealed no significant difference to that of the positive control indicating that sample 1 may be potent in delaying visceral pain perception even at a very low dose comparable to the commercial drug diclofenac. The abdominal stretches observed in the negative control group indicate that there was sensitization of pain in the affected area by the release of free arachidonic acid from some tissue phospholipids which in turn have been transformed to prostaglandins (Hasan et al., 2009). The acetic acid writhing test is sensitive in examining peripheral acting analgesics through localizing acute inflammatory responses that could be associated with the presence of prostaglandins (Hasan et al., 2010). Prostaglandin E2 (PGE2) with other endogenous mediators like prostaglandin $\mathrm{F} 2 \alpha(\mathrm{PF} 2 \alpha)$ and other lipooxygenase products stimulate nociceptive neurons that could result in abdominal responses (De Souza et al., 2009), thus inhibiting the synthesis of pros- taglandin and reducing the writhing frequency in mice (Akter et al., 2008).

Carrageenan-induced lung pleurisy was used to determine the anti-inflammatory activity of sample 1 . There was a reduced number of WBC in the pleural cavity in mice administered with sample 1 following a non-dose-dependent interaction. Intraperitoneal injection of carrageenan triggers the intense inflammatory response with the formation of exudates which mainly contain neutrophils (Horakova et al., 1980). An increase in the level of mast cells and histamine could indicate the first phase of inflammation followed by the release of plasma protease, lysosomes, and prostaglandins that induce pyrogen production, pain, and increase vascular permeability. This phase is the common target of most anti-inflammatory drugs (Arul et al., 2004). All doses of sample 1 have shown significant reduction in the amount of leukocytes counted after carrageenan assault which was just similar to the effects of diclofenac. This could be attributed to the antihistaminic activity as indicated in the pharmacological description of diclofenac (MIMS, 2010) which inhibits the enzyme cyclooxygenase leading to decreased proinflammatory agents. Such action prevents from vasodilation and decreases the vascular permeability (Pendota et al., 2009). Furthermore, the decreased level of histamine could potentially inhibit biosynthesis, release, and activity of prostaglandin.

A previous study (Simirgiotis et al., 2008) on $S$. samarangense crude extracts indicated its high analgesic and anti-inflammatory properties. Sample 1 in this sense has an immense potential to reduce acute inflammation by attenuated pleural exudation and migration of WBC caused by an irritant such as carrageenan. The current study suggests that sample 1 is also responsible for the high analgesic and anti-inflammatory activities observed in this previous investigation of $S$. samarangense crude extracts.

Sample 1 did not cause any significant effect on dechorionated 24-hpf and 36-hpf embryos. Treatments with sample 1 , however, were found to have significant effects on morphology and hatching frequency of embryos to intact chorion. Since direct exposure of the embryos to sample 1 did not reveal any observable difference to the negative control, it may have minimal contribution to the observed effects following the treatments. The presence of chorion allows the diffusion of gases (Iconomidou et al., 2000). The overall integrity 
of the chorion may have been affected, thereby limiting the normal transit of materials such as respiratory gases (Mendelsohn et al., 2008). Hypoxic condition in tissues may result in particular changes in the carbohydrate metabolism, a possible increase in the nitric oxide level, and stimulated production of hemoglobin (Padilla and Roth, 2001). As demonstrated by Ton et al. (2003) zebrafish exposed to hypoxic conditions during development resulted in a shut-down of energy-requiring processes (i.e. protein synthesis), suppressed locomotion, and cell growth and division. Treatment with sample 1 may have created a hypoxic environment for the embryos due to a possible loss of chorionic integrity. Inhibition of the exchange of respiratory gases such as oxygen and carbon dioxide between the embryo and environment may have triggered certain teratologic switch. The chorion serves as the major respiratory organ upon which carbon dioxide and oxygen pass through (Mendelsohn et al., 2008). As a result, the embryo is indirectly affected by sample 1 through disruption of the passage of gases needed for its development, causing very high mortality and a delay in hatching.

Akter R., Hasan S., Siddiqua S., Majumder M., Hossain M., Alam M., Haque S., and Ghani A. (2008), Evaluation of analgesic and antioxidant potential of the leaves of Curcuma alismatifolia Gagnep. Sci. J. Pharmacol. Sci. 1, 3-9.

Amor E., Villasenor I., Yasin A., and Choudhary M. (2004), Prolyl endpeptidase inhibitors from Syzygium samarangense (Blume) Merr. \& L. M. Perry. Z. Naturforsch. 59c, 86-92.

Amor E., Villasenor I., Antemano R., Perveen Z., Concepcion G., and Choudhary M. (2007), Cytotoxic Dmethylated chalcones from Syzygium samarangense. Pharm. Biol. 45, 777-783.

Arul V., Miyazaki S., and Dhananjayan M. (2004), Studies on the anti-inflammatory, antipyretic and analgesic properties of the leaves of Aegles marmelos Corr. J. Ethnopharmacol. 96, 159-163.

De Pascual Teresa J., Urones J. G., Marcos I. S., Besabe P., Sexnero Cuadrado M. J., and Fernandez Moro R. (1987), Triterpenes from Euphorbia broteri. Phytochemistry 26, 1767-1776.

De Souza E., de Lira D., de Quieroz A., da Silva D., de Aquino A., Mella E., Lorenzo V., de Miranda G., de Araujo-Junior J., de Oliveira Chaves M., BarbosaFilho J., de Athayde-Filho P., de Oliveira Santos B., and Alexandre-Moreira M. (2009), The anti-nociceptive and anti-inflammatory activities of caulerpin, a bisindole alkaloid isolated from seaweeds of the genus Caulerpin. Mar. Drugs 7, 687-704.

\section{Conclusions}

Sample 1 demonstrated analgesic activity at an effective dose of $6.25 \mathrm{mg} / \mathrm{kg} \mathrm{BW}$ and anti-inflammatory activity at an effective dose of $12.5 \mathrm{mg} / \mathrm{kg}$ $\mathrm{BW}$, suggesting that it is of high pharmacological importance and could possibly be used as source of phytopharmaceuticals. The present study also demonstrated the relative toxicity potential of the mixture of sample 1 on zebrafish embryos in both dechorionated and intact chorion experiments. Sample 1 had no effect on the mortality and teratology of dechorionated zebrafish embryos. However, there were incidences but negligible abnormalities observed in all treatments. Hatching was delayed in embryos with intact chorion treated with sample 1 , hence it is non-toxic at the dose tested. It has, however, a potential effect on chorionic membranes that may impair respiratory gas diffusion across the membrane system. Results of the study suggest the possible importance of sample 1 as bioactive substance capable of inhibiting pain sensitivity and inflammation at a dose comparable to diclofenac with minimal to no effects on embryonic systems.

Ghayur M., Gilani A., Khan A., Amor E., Villaseñor I., and Choudhary M. (2006), Presence of calcium antagonist activity explains the use of Syzygium samarangense in diarrhea. Phytother. Res. 20, 49-52.

Grotto F. and Sulman F. (1967), Modified receptacle method for animal analgesimetry. Arch. Int. Pharmacodyn. Ther. 165, 152-159.

Guevarra B., Claustro A., Madulid R., Aguinaldo A., Espeso E., Guevara B., Nonato M., Quinto E., Santos M. A., de Castro-Bernas G., Gonzales R., del Castillo-Solevilla R., and Ysrael M. (2005), A Guidebook to Plant Screening: Phytochemical and Biological. Research Center for the Natural Sciences, University of Sto. Tomas Espana, Manila.

Hasan S., Jamila M., Majumder M., Akter R., Hossain M., Mazumder M., Alam M., Jahangir R., Rana S., Arif M., and Rahman S. (2009), Analgesic and antioxidant activity of the hydromethanolic extract of Mikania scandens (L.) Willd. leaves. Am. J. Pharmacol. Toxicol. 4, 1-7.

Hasan S., Hossain M., Akter R., Jamila M., Mazumder M., Alam M., Faruque A., Rana S., and Rahman S. (2010), Analgesic activity of the different fractions of the aerial parts of Commelina benghalensis Linn. Int. J. Pharmacol. 6, 63-67.

Horakova Z., Bayer B., Almeida A., and Beaven M. (1980), Evidence that histamine does not participate carrageenan-induced pleurisy in rat. Eur. J. Pharmacol. 62, 17-25. 
Iconomidou V., Chryssikos D., Gionis V., Pavlidis M., Paipetis A., and Hamodrakas S. (2000), Secondary structure of chorion proteins of the teleostan fish Dentex dentex by ATR FT-IR and FT-raman spectroscopy. J. Struct. Biol. 132, 112-122.

Kimmel C., Ballard W., Kimmel S., and Ullmann B. (1995), Stages of embryonic development of the zebrafish. Dev. Dyn. 203, 253-310.

Kitambi S., McCulloch K., Peterson R., and Malicki J. (2009), Small molecule screen for compounds that affect vascular development in the zebrafish retina. Mech. Dev. 126, 464-467.

Kuo Y., Yang L., and Lin L. (2004), Isolation and immunomodulatory effect of flavonoids from Syzygium samarangense. Planta Med. 70, 1237-1239.

Liu X. K., Li Z. R., Qui M. H., and Nie R. L. (1998), Triterpene constituents from Balanophora indica. Acta Bot. Yunnan 20, 369-373.

Mendelsohn B., Kassebaum B., and Gitlin J. (2008), The zebrafish embryo as a dynamic model of anoxia tolerance. Dev. Dyn. 237, 1780-1788.

MIMS (2010), Philippines CMP Medica: Diclofenac. Available from: http://www.mims.com/Page.spx? menuid=mng\&name $=$ diclofenac $\&$ CTRY $=$ PH\&brief $=$ false\# Actions. (accessed on April, 5 2010).

Padilla P. and Roth M. (2001), Oxygen deprivation causes suspended animation in the zebrafish embryo. Proc. Natl. Acad. Sci. USA 98, 7331-7335.

PALAS (2002), Code of Practice for the Care and Use of Laboratory Animals in the Philippines. The Committee on Code of Practice of the Philippine Association for Laboratory Animal Sciences, Manila.

Parmar V., Jain S. C., Gupta S., Talivar S., Rajawanshi V. K., Kumar R., Azim A., Malhotra S., Kumar N., Jain R., Sharma N. K., Tyagi O. M., Lawrie S. J., Errington W., Howarth O. W., Olsen C. E., and Singh S. K. (1998), Polyphenol and alkaloids from piper species. Phytochemistry 49, 1069-1078.
Pendota S., Yakubu M., Grierson D., and Afolayan A. (2009), Anti-inflammatory, analgesic and antipyretic activities of the aqueous extract of Hippobromus pauciflorus (L.f) Radlk leaves in male Wistar rats. Afr. J. Biotechnol. 8, 2036-2041.

Raga D., Cueto J., Ganacias R., and Mandia E. (2010), Anti-nociceptive and anti-inflammatory activities of Atalantia retusa Merr. Phcog. J. 2, 173-177.

Ragasa C., Tiu F., and Rideout J. (2004), New cycloartenol esters from Ixora coccinea. Nat. Prod. Res. 18, 319-323.

Ragasa C. Y., Ngo H.-T., and Rideout J. (2005), Terpenoids and sterols from Lagerstroemia speciosa. J. Asian Nat. Prod. Res. 7, 7-12.

Ragasa C. Y., Alimboyoguen A. B., Urban S., and Raga D. D. (2008), A bioactive diterpene from Smallanthus sonchifolius. Nat. Prod. Commun. 3, 1663-1666.

Ragasa C., Puno M., Sengson J., Shen C., Rideout J., and Raga D. (2009), Bioactive triterpenes from Diospyros blancoi. Nat. Prod. Res. 23, 1252-1258.

Resurreccion-Magno M., Villasenor I., Harada N., and Monde K. (2005), Antihyperglycaemic flavonoids from Syzygium samarangense (Blume) Merr. and Perry. Phytother. Res. 19, 246-251.

Simirgiotis M., Adachi S., To S., Yang H., Reynertson K., Basile M., Gil R., Weinstein B., and Kennelly E. (2008), Cytotoxic chalcones and antioxidants from the fruits of Syzygium samarangense (wax jambu). Food Chem. 107, 813-819.

Ton C., Stamatiou D., and Liew C. (2003), Gene expression profile of zebrafish exposed to hypoxia during development. Physiol. Genomics 13, 97-106.

Villasenor I. M., Cabrera M. A., Meneses K. B., Rivera V. R. R., and Villasenor R. M. (1998), Comparative antidiabetic activities of some medicinal plants. Philipp. J. Sci. 127, 261-266.

Westerfield M. (2007), The Zebrafish Book: A Guide for the Laboratory Use of Zebrafish (Danio rerio), $15^{\text {th }}$ ed. Institute of Neuroscience, University of Oregon Press, Eugene, OR, USA. 